Available online at GSC Online Press Directory

GSC Biological and Pharmaceutical Sciences

e-ISSN: 2581-3250, CODEN (USA): GBPSC2

Journal homepage: https://www.gsconlinepress.com/journals/gscbps

(RESEARCH ARTICLE)

\title{
Effect of sleep, breakfast and physical activity on test anxiety and psychological distress
}

\author{
Nusrat Aziz * \\ Department of Physiology, Faculty of Medicine, Umm Al-Qura University, Makkah 24382, Kingdom of Saudi Arabia.
}

Publication history: Received on 10 November 2020; revised on 20 November 2020; accepted on 24 November 2020

Article DOI: https://doi.org/10.30574/gscbps.2020.13.2.0382

\begin{abstract}
Introduction: Student psychological distress, emotional disorders, burnout and suicidal ideation are a bitter reality of our present day competitive educational system. Stress is heightened during examination periods. The essentiality of predictors is to find coping techniques to reduce test anxiety and psychological distress, simultaneously maintaining healthy stress and a healthy body, which is needed to drive performance.

Material and methods: A cross-sectional study of female medical students for test anxiety and psychological distress was done on, the effects of sleep the night before examination, breakfast consumption before exam and students involvement with exercise or sports. Westside test anxiety scale and Kessler's psychological distress K10 scale was used to assess the test anxiety and psychological distress along with self-reporting of breakfast consumption, involvement in exercise or sports and sleep duration in the night before exam.

Results: This study shows significant negative correlation of test anxiety and psychological distress with duration of sleep. The mean test anxiety and psychological distress were higher with less sleep but odd ratio was not significant. The odds ratio of high Psychological distress were significantly lesser with physical activity Exp(B) 0.562 (95\%CI 0.333, 0.949 ) and with breakfast consumption $\operatorname{Exp}(\mathrm{B}) 0.456$ (95\%CI $0.268,0.777)$. The odds ratios for high test anxiety with exercise and breakfast consumption are lower but not significant.

Conclusion: Educational institutions should teach students on the beneficial effect of sleep, breakfast and exercise to reduce academic stress which can enhance students' performance.
\end{abstract}

Keywords: Psychological distress; Test anxiety; Exercise; Sleep; Breakfast

\section{Introduction}

Stress has become an integral part of a student's life and more so in medical students attributable to reasons such as increased workload and higher expectations. The global prevalence of anxiety was found to be $33.8 \%$ and with higher values in Middle East and Asian countries [1] Anxiety and its effect become greatly increased during the testing periods such as examinations. Testing situations are viewed as a threat to a person self-worth activating a stress response which is further escalated by fear of failure.

Test anxiety is occurrence of intense physiological, cognitive, and/or behavioral symptoms of stress before or during test-taking situations that can affect test performance [2]. Test anxiety is a widespread problem in university students which is detrimental to performance during examinations by decreasing cognitive skills, decreasing recall memory, hampering good study and increasing errors [3,4]Test anxiety causes low self-esteem and amotivation [5,6]. Test

\footnotetext{
${ }^{*}$ Corresponding author: Dr.Nusrat Aziz

Department of Physiology, Faculty of Medicine, Umm Al-Qura University, Makkah 24382, Kingdom of Saudi Arabia.
}

Copyright (C) 2020 Author(s) retain the copyright of this article. This article is published under the terms of the Creative Commons Attribution Liscense 4.0. 
anxiety can decrease GPA and in reverse low GPAs can lead to Test anxiety [6,7]. Test anxiety is a state of sympathetic overdrive or hyper-arousal [8] and therefore it can be affected by such factors like sleep, regular physical activity, and breakfast or food consumption during the examination period. Test anxiety is associated with psychological distress [28]. Psychological distress is increased with increased workload, less leisure time and higher expectancy from family and friends. Test anxiety and psychological distress has become a burden on student's life.

Our study aimed to analyze the effect of sleep duration in the night before examination, effect of skipping breakfast before exams and involvement in sports on test anxiety and psychological distress during examinations in university students.

\subsection{Sleep}

Sleep is an essential part of our circadian rhythm. Sleep helps in repair, restoration of neurotransmitters, detoxification of metabolites and consolidation of memory. Not enough sleep in the night before exam effects cognition, impairs memory and decreases performance. Apart from these effects it disturbs the circadian rhythm producing nausea, fatigue, lethargy and drowsiness. Thus sleep is an important part of our physiology and deprivation of which may lead to impaired neural functioning and decreased performance mounting to stress, apprehension and self-doubt. Sleep and anxiety have a bidirectional relation with each other seen as increasing anxiety with sleep deficiency vice versa. Depression and anxiety including test anxiety has been associated with poor sleep quality $[9,10]$.

\subsection{Skipping Breakfast}

The symptoms of test anxiety are more in students who have skipped the breakfast before examination. Akbari et al observed that breakfast consumption was associatedwith lower test anxiety [11] Not taking any food in morning produces a state of inadequate energy substrate leading to release of hormones such as Cortisol with stress independent hyperactivity of hypothalamo-pituitary adrenal axis[12]Skipping breakfast has been found to have higher risk of depression independent of other lifestyle factors such as sleep quality, physical activity, smoking and alcohol consumption $[13,14,15]$. A Korean study on 62276 adolescents showed that breakfast skippers tend to take more caffeinated drinks, carbonated drinks and convenience store food than regular breakfast eaters and show higher stress, mood disorders, suicidal ideation, decreased vigorous physical activity and lower grades [16] and use of caffeinated energy drinks were shown to increase test anxiety [17]

\subsection{Sports/physical activity}

Physical activity in any form like exercise or sports has been known to decrease stress and is beneficial in treatment of anxiety and mood disorders. A meta-analysis has shown that self-reported physical activity exerts a protective effect against the emergence of anxiety. [18]Test anxiety is considerably less in physically active students and sedentary behavior increases anxiety risk[19,20] Physical fitness is associated with lower anxiety in children [21] John Ratey from Harvard University explains that exercise increases the neurotransmitters like serotonin,Gamma amonobutyric acid (GABA) Brain derived neurotrophic factor(BDNF) and endocannibinoids and also increase frontal activity to control amygdala hyper-responsiveness there by plays a great role in decreasing anxiety[22].

\section{Material and methods}

A crossectional study was done with participation of students of Umm Al Qura University female medical college. 404 female participants were included in study. The ages of the students were mainly 18-25 with two students of 26 and 27 years. Students who had been diagnosed with any psychiatric disorder or on any prescription medication for anxiety or depression were excluded from study. The students were approached during the period of examinations. This study was approved by Biomedical Ethics Committee of Umm Al-Qura University. The students were informed about the details of study and a signed consent was taken. They were encouraged to join voluntarily and those who refused were not forced to participate.

- $\quad$ Test anxiety was checked with Westside Test Anxiety Scale devised by Driscoll. It includes 10 questions about symptoms of anxiety, recall memory and poor cognition. The responses are in likert score of 1-5 with scores more than 3 as high test anxiety needing intervention. Driscoll got a 0.44 coefficient of validity for the scale [23] The alpha reliability measured by Rajiah in his study was 0.89. [24]

- Assessment of psychological distress was done by Kesslers psychological distress scale K10. It includes 10 questions about anxiety and depressive symptoms in the last 4 weeks. It has good precision in the 90th-99th percentile range of the population. The sensitivity, specificity and Cronbach coefficient were $0.95,0.54$ and 0.84 
as found by Arnoud et al [25]. The scores range from 10-50 with scores more than 30 as very high psychological distress requiring intervention.

- Along with the above two scales the students were asked about the duration of sleep in the night before exam, the consumption of any breakfast before exam and involvement in any exercise or sports.

- Statistical analysis was done with Statistics Package for Social sciences version 20 (SPSS 20). The data was analyzed for descriptive studies, Pearson's correlations and logistic regression analysis along with statistical graphs.

\section{Results}

Participants were 411 female medical students with mean age of 21.7445 (S.D.-1.626). The frequency of year 1 students was 103 (25.1\%), year 2: 77(18.6\%), year 3: 81(19.7\%), year 4: $74(18 \%)$ and year 5: 76(18.5\%). Their Westside test anxiety scale and Kessler's Psychological distress scale K10 scores were analyzed. Binary logistic regression analysis was done with test anxiety as dichotomous categorical variable with values as low ( $<3$ score) and high test anxiety ( $>3$ score) with psychological distress as continuous variable. The results showed that the odds of high test anxiety increase with one score rise of psychological distress by $\operatorname{Exp}(\mathrm{B})=1.121$ times (95\%CI 1.085 and 1.159). The odds ratio for high test anxiety with high psychological distress was 3.773 (95\%CI 2.137, 6.663). Shown below is the scatterplot (Fig. 1) between test anxiety and psychological distress showing a positive correlation.

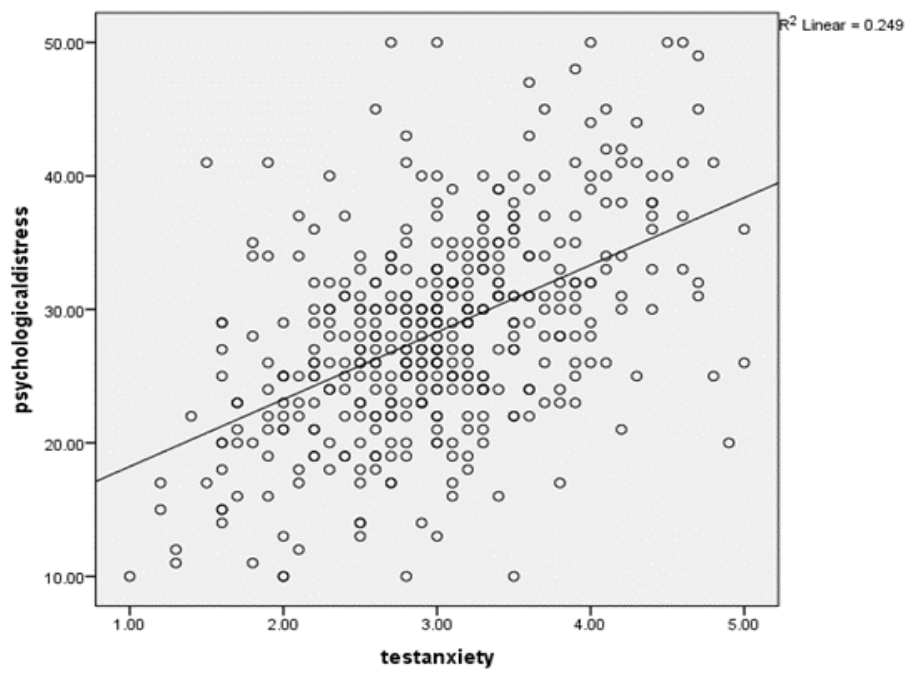

Figure 1 scatterplot showing positive correlation between test anxiety and psychological distress

The students were asked about the number of hours they had slept in the night before examination day. 56 (13.9\%) students did not sleep at all, 180(44.6\%) had less than 3 hours of sleep, 141(34.9\%) slept 3-6 hours and only 27(6.7\%) had more than 6 hours of sleep. Around $58.4 \%$ had slept less than 3 hours or did not sleep at all. Students who did not sleep or slept less than 3 hours showed mean test anxiety of 3.073 and 3.083 respectively compared to 2.877 and 2.867 for those who slept 3-6 hours and more than 6 hours respectively (Fig. 2). The mean psychological distress was high with 29.05 and 29.47 for no sleep and less than 3 hours of sleep respectively and for 3-6 hours and more than 6 hours sleep duration it was 2.877 and 2.867 (Fig. 3). Pearsons correlation analysis showed negative correlation(r=-.113) with statistical significance $0.023(\mathrm{p}<0.05$ ) (Table 1 ). Multinomial logistic regression for high test anxiety for those who did not sleep at all , odds ratio were $\operatorname{Exp}(B)=1.343(95 \% \mathrm{CI} .543,3.377)$, and for sleep less than 3 hours the odds ratio $\operatorname{Exp}(B)=1.494(95 \% C I . .662,3.371)$ and for 3-6 hours of sleep the odds ratio are $\operatorname{Exp}(B)=1.342(95 \% \mathrm{CI} .586,3.071)$ which was not statistically significant. Psychological distress was also negatively correlated with $\mathrm{r}=-.141$ with statistical significance of $0.004(\mathrm{p}<0.01)$. (Table 2). Multinomial logistic regression for high psychological distress with students who did not sleep at all the night before exam the odds ratio were $\operatorname{Exp}(B)=2.381(95 \% \mathrm{CI} .688,8.236)$, and for sleep less than 3 hours the odds ratio $\operatorname{Exp}(B)=1.771(95 \% \mathrm{CI} .651,4.819)$ and for 3-6 hours of sleep the odds ratio are $\operatorname{Exp}(B)=$ .899 (95\%CI .335, 2,410) 


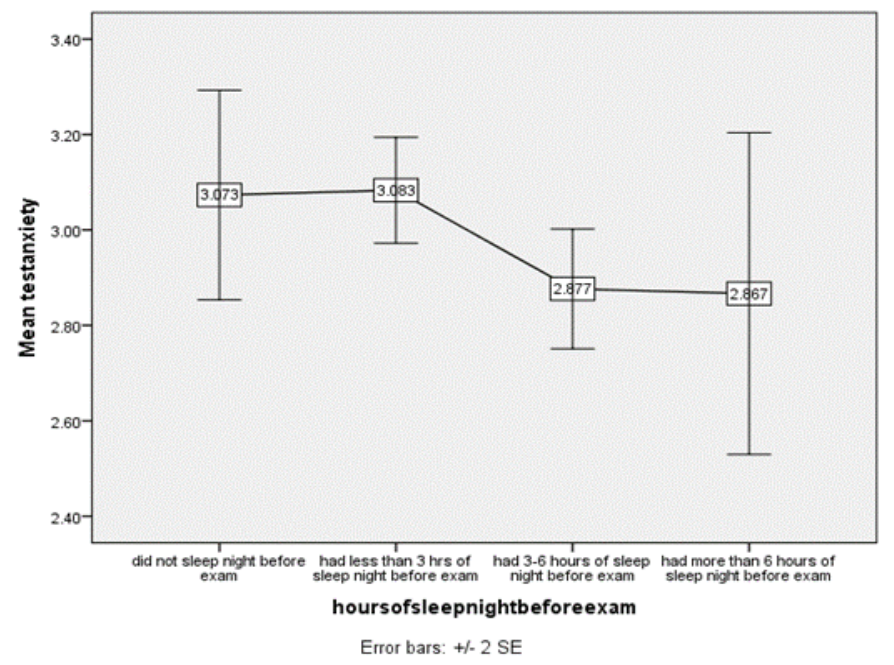

Figure 2 Mean test anxiety with duration of sleep in the night before exam

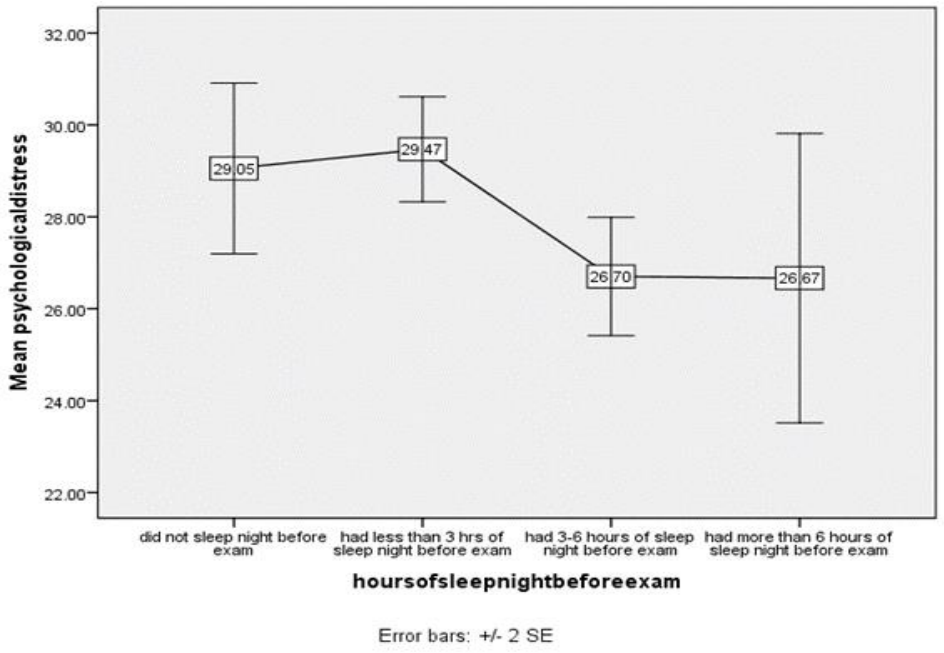

Figure 3 Mean psychological distress with duration of sleep in the night before exam

Table 1 Negative correlation between test anxiety and duration of sleep in night before examination

\begin{tabular}{|c|c|c|c|}
\hline \multicolumn{4}{|c|}{ Correlations } \\
\hline & & Test anxiety & $\begin{array}{l}\text { Hours of sleep night } \\
\text { before exam }\end{array}$ \\
\hline \multirow{3}{*}{ Test anxiety } & Pearson Correlation & 1 & $-.113^{*}$ \\
\hline & Sig. (2-tailed) & & .023 \\
\hline & $\mathrm{N}$ & 411 & 404 \\
\hline \multirow{3}{*}{$\begin{array}{l}\text { Hours of sleep night } \\
\text { before exam }\end{array}$} & Pearson Correlation & $-.113^{*}$ & 1 \\
\hline & Sig. (2-tailed) & .023 & \\
\hline & $\mathrm{N}$ & 404 & 404 \\
\hline
\end{tabular}


Table 2 Negative correlation between psychological distress and duration of sleep in night before examination

\begin{tabular}{|l|l|l|l|}
\hline \multicolumn{4}{|c|}{ Correlations } \\
\hline \multicolumn{2}{|c|}{} & Psychological distress & $\begin{array}{l}\text { Hours of sleep night } \\
\text { before exam }\end{array}$ \\
\hline \multirow{3}{*}{$\begin{array}{l}\text { Psychological } \\
\text { distress }\end{array}$} & Pearson Correlation & 1 & $-.141^{* *}$ \\
\cline { 2 - 4 } & Sig. (2-tailed) & & .004 \\
\cline { 2 - 4 } $\begin{array}{l}\text { Hours of sleep night } \\
\text { before exam }\end{array}$ & $\mathrm{N}$ & 411 & 404 \\
\cline { 2 - 4 } & Pearson Correlation & $-.141^{* *}$ & 1 \\
\cline { 2 - 4 } & Sig. (2-tailed) & .004 & 404 \\
\cline { 2 - 4 } & $\mathrm{N}$ & 404 & \\
\hline
\end{tabular}

$51 \%$ of students did not take any breakfast before the exam and $49 \%$ said they had breakfast. The mean test anxiety was higher that is 3.02 for breakfast skippers and 2.96 for those who had taken breakfast. The mean psychological distress was also higher with 28.94 for breakfast skippers than 27.55 for those who had taken breakfast. There was no statistically significant association either by correlation or Odds ratio of breakfast consumption for test anxiety. Binary logistic regression analysis with high and low psychological distress as dependent variable and breakfast skippers and breakfast takers as covariate showed Odds Ratio $\operatorname{Exp(B)~} 0.456(95 \% \mathrm{CI} 0.268,0.777) \mathrm{p}=0.004$. So breakfast consumption was associated with lower risk of psychological distress as has been seen in other studies too. The odds ratio for breakfast consumption and high test anxiety were also lesser with $\operatorname{Exp}(B) .791$ (95\%CI .535, 1.170) p=0.240 but not significant.

$273(67.41 \%)$ students said they were not involved in any exercise or sports activity while $132(32.59 \%)$ were involved in exercise or sports activities. The bar diagram (Fig.4) shows more number of students not involved in exercise/sports are likely to high test anxiety compared to group involved in exercise or sports. The mean test anxiety for those not involved in test anxiety was higher with 3.027 score compared to 2.924 of those who did exercise or sports and showed no statistical significant association. The odds ratio with binary logistic regression for high test anxiety with exercise is $\operatorname{Exp}(\mathrm{B}) 0.688$ (95\% CI 0.454, 1.045)p=0.08. The mean psychological distress was lower in students who did exercise or sports with 27.02 compared to those who did not with 28.82. There was significant negative correlation with between exercise/sports with psychological distress with $r=.110$ and $p=0.027(p<0.05)$ (Table 3). The odds ratio for exercise and high psychological distress with binary logistic regression were $\operatorname{Exp}(\mathrm{B}) 0.562(95 \% \mathrm{CI} 0.333,0.949) \mathrm{p}=0.031$.

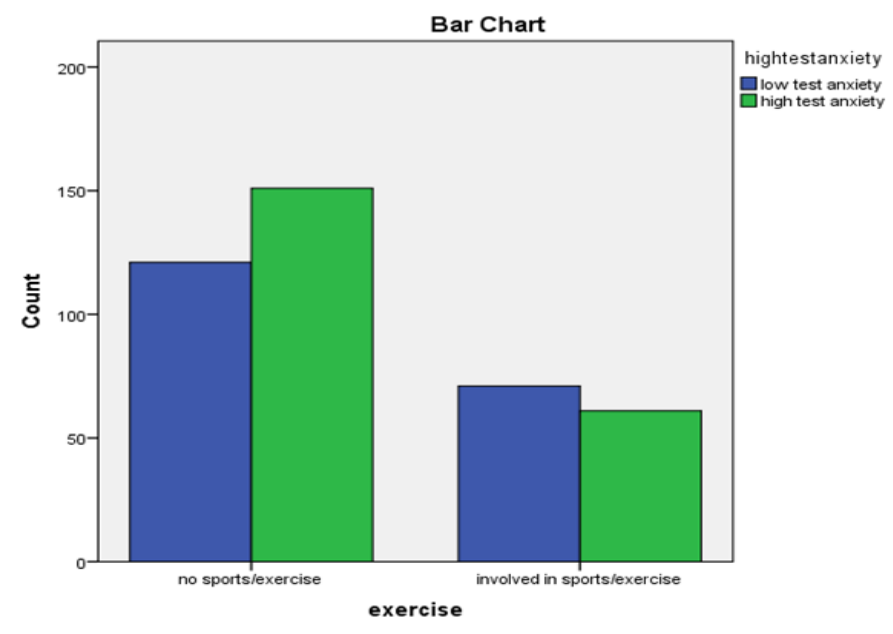

Figure 4 Higher counts for high test anxiety with students not involved in exercise or sports activity 
Table 3 Negative correlation between psychological distress and exercise/sports activity

\begin{tabular}{|c|c|c|c|}
\hline \multicolumn{4}{|c|}{ Correlations } \\
\hline & & Exercise/ sports & Psychological distress \\
\hline \multirow{3}{*}{ Exercise /sports } & Pearson Correlation & 1 & $-.110^{*}$ \\
\hline & Sig. (2-tailed) & & .027 \\
\hline & $\mathrm{N}$ & 405 & 405 \\
\hline \multirow{3}{*}{ Psychological distress } & Pearson Correlation & $-.110^{*}$ & 1 \\
\hline & Sig. (2-tailed) & .027 & \\
\hline & $\mathrm{N}$ & 405 & 411 \\
\hline
\end{tabular}

\section{Discussion}

Academic stress is still underdiagnosed and undertreated despite increasing research being done on this aspect. The prevalence of test anxiety in female university students in our study was 53\% similar to 51\% in United States of America [26] and 55. 8\% in Turkey [27]. There was significant association between test anxiety and psychological distress with positive correlation as observed in a Malaysian study [28]. Each unit increase in Psychological distress as per K10 Scale increase likelihood of high test anxiety by $12 \%$ and those with high psychological distress were $277 \%$ more likely to have high test anxiety too. 58.5\% of students reported they have slept less than 3 hours the night before exam or did not sleep all and showed mean test anxiety of 3.078 (score $>3$ ) is high test anxiety needing intervention) and mean psychological distress 29.26 (score $>30$ is high psychological distress). The duration of sleep before examination has significant negatively correlated with test anxiety and psychological distress. This can be bidirectional effect between stress and sleep. Fakhari et al has found that sleep duration correlates positively with examination scores thus helping in high achievement [29]. Breakfast consumption is has lowering effect on test anxiety [30, 31]. In this study the prevalence of breakfast skippers before exam 51\% with mean test anxiety of 3.02 compared 2.96 for breakfast. The odds ratio for breakfast consumption for high test anxiety was 0.915 (95\% CI 0.710, 1.180) which was not significant. The odds ratio for breakfast consumption and high psychological distress are significant with $\operatorname{Exp(B)} 0.456$ (95\%CI $0.268,0.777) \mathrm{p}=0.004$. Therefore we can say that breakfast skippers are about $54.4 \%$ less likely to have high psychological distress. So breakfast consumption is protective against mental disorders as has also been observed in other studies also $[13,14,15,16,32]$ The number of respondents reported to be involved in exercise or sports were only $32.9 \%$ of the participants. The mean test anxiety students were not involved in exercise or sports and those were involved were 3.027 and 2.924 with no significant association with test anxiety. The odds ratio by logistic regression analysis for test anxiety and exercise/ sports was 0.688 (95\%CI $0.454,0.045) \mathrm{p}=0.08$. The mean psychological distress was lesser for students involved in exercise than those who were not. There was negative significant correlation between exercise and psychological distress with $\mathrm{r}=-0.110 \mathrm{p}=0.027$. The odds ratio for high psychological distress were $0.562(95 \%$ CI $0.333,0.949) \mathrm{p}=0.031$. Thus those who were involved in physical activity such as exercise or sports were 43.8\% less likely to develop high psychological distress.

\section{Conclusion}

It is important for students to regulate their stress and emotions so as to perform better in their pursuit of achievement of higher GPAs. Lifestyle adjustment like regular exercise, habit of taking healthy breakfast and good sleep can reduce psychological distress and test anxiety and increase their resilience. Educational institutions should make mandatory counseling to teach students about the detrimental effects of test anxiety and psychological distress and the ways to decrease them to be able to perform to their capacity.

\section{Compliance with ethical standards}

\section{Acknowledgments}

I would like to thank the students for their participation. I would also like to thank my husband Fazal Mustafa Ali Khan for his continual support and encouragement 


\section{Disclosure of conflict of interest}

The authors declare there is no conflict of interest and no financial aid was taken for this

\section{Statement of ethical approval}

Ethical approval was taken from the Biomedical Ethics Committee of Umm Al-Qura University

\section{Statement of informed consent}

Informed and signed consent was taken. Participant identity was kept anonymous.

\section{References}

[1] Quek TT, Tam WW, Tran BX, Zhang M, Zhang Z, Ho CS, Ho RC. The Global Prevalence of Anxiety Among Medical Students: A Meta-Analysis. International journal of environmental research and public health. 2019; 16(15): 2735.

[2] Sawka-Miller KD. Test Anxiety. In: Goldstein S, Naglieri J.A. (eds) Encyclopedia of Child Behavior and Development. Springer, Boston, MA. 2011.

[3] Spielberger CD. Test Anxiety Inventory. In The Corsini Encyclopedia of Psychology (eds I.B. Weiner and W.E. craighead). 2010.

[4] Trifoni, Anisa Shahini, Mostafa. How Does Exam Anxiety Affect the Performance of University Students?. Mediterranean Journal of Social Sciences. 2011; 2: 93-100.

[5] Saravanan, C., Kingston, R., \& Gin, M. Is Test Anxiety a Problem Among Medical Students: A Cross Sectional Study on Outcome of Test Anxiety among Medical Students?. International Journal Of Psychological Studies. 2014; 6(3). doi: 10.5539/ijps.v6n3p24

[6] Sideeg A. Test anxiety, self-esteem, gender difference, and academic achievement: the case of the students of medical sciences at Sudanese universities: a mixed methods approach. British Journal of Arts and Social Sciences. 2015; 9(11): 39-59.

[7] Macauley K, Plummer L, Bemis C, Brock G, Larson C, Spangler J. Prevalence and Predictors of Anxiety in Healthcare Professions Students. Health Professions Education. 2018; 4(3): 176-185.

[8] Hahn H, Kropp P, Kirschstein T, Rücker G, Müller-Hilke B. Test anxiety in medical school is unrelated to academic performance but correlates with an effort/reward imbalance. PLoS ONE. 2017; 12(2): e0171220.

[9] Rezaei M, Khormali M, Akbarpour S, Sadeghniiat-Hagighi K, Shamsipour M. Sleep quality and its association with psychological distress and sleep hygiene: a cross-sectional study among pre-clinical medical students. Sleep science (Sao Paulo, Brazil). 2018; 11(4): 274-280.

[10] Köse S, Yllmaz Ş, Göktaş S. The relationship between exam anxiety levels and sleep quality of senior high school students. JOURNAL OF PSYCHIATRIC NURSING. 2020; 9(2): 105-111.

[11] Akbari V, Asayesh H, Sharififard F, Qorbani M, Elahi A, Heidarpour A. consumption as a test anxiety predictor among paramedical students. Journal of nursing and Midwifery sciences. 2020; 7: 47-51.

[12] Witbracht M, Keim NL, Forester S, Widaman A, Laugero K. Female breakfast skippers display a disrupted cortisol rhythm and elevated blood pressure. Physiology \& behavior. 2015; 140: 215-221.

[13] Miki T, Eguchi M, Kuwahara K, Kochi T, Akter S, Kashino I, Hu H, Kurotani K, Kabe I, Kawakami N, Nanri A, Mizoue T. Breakfast consumption and the risk of depressive symptoms: The Furukawa Nutrition and Health Study. Psychiatry research. 2019; 273: 551-558.

[14] Ren Z, Cao J, Cheng P, Shi D, Cao B, Yang G, Liang S, Du F, Su N, Yu M, Zhang C, Wang Y, Liang R, Guo L, Peng L. Association between Breakfast Consumption and Depressive Symptoms among Chinese College Students: A Cross-Sectional and Prospective Cohort Study. International journal of environmental research and public health. 2020; 17(5): 1571.

[15] Zhu Z, Cui Y, Gong Q, Huang C, Guo F, Li W, Zhang W, Chen Y, Cheng X, Wang Y. Frequency of breakfast consumption is inversely associated with the risk of depressive symptoms among Chinese university students: A cross-sectional study. PloS one. 2019; 14(8): e0222014. 
[16] Lee HJ, Kim CH, Han I, Kim SH. State According to Breakfast Consumption in 62276 South Korean Adolescents, Iran J Pediatr. Online ahead of Print. 2019; 29(6): e92193.

[17] Nusrat Aziz, Abdulhalim Salim Serafi. Psychostimulants - a boon or bane during examinations. GSC Biological And Pharmaceutical Sciences. 2020; 13(1): 010-018.

[18] Schuch FB, Stubbs B, Meyer J, et al. Physical activity protects from incident anxiety: A meta-analysis of prospective cohort studies. Depress Anxiety. 2019; 36: 846- 858.

[19] Teychenne M, Costigan SA, Parker K. The association between sedentary behaviour and risk of anxiety: a systematic review. BMC Public Health. 2015; 15: 513.

[20] Cleveland A, "Move More, Stress Less: Exploring the Relationship between Physical Activity and Test Anxiety in Undergraduate Nursing Students" (2017). Undergraduate Honors Theses. 17.https://digitalcommons.gardnerwebb.edu/undergrad-honors/17

[21] Li Y, Xia X, Meng F, Zhang C. Association Between Physical Fitness and Anxiety in Children: A Moderated Mediation Model of Agility and Resilience. Frontiers in public health. 2020; 8: 468.

[22] John J. Ratey, M. (2020). Can exercise help treat anxiety? - Harvard Health Blog. Retrieved 23 November 2020.

[23] Driscoll R. Westside Test Anxiety Scale Validation. 2007; 1-6.

[24] Rajiah K, Saravanan C. The effectiveness of psychoeducation and systematic desensitization to reduce test anxiety among first-year pharmacy students. American Journal of Pharmaceutical Education. Nov 2014; 78(9): 163.

[25] Arnaud B, Malet L, Teissedre F, Izaute M, Moustafa F, Geneste J, Schmidt J, Llorca PM, Brousse G. Validity study of Kessler's psychological distress scales conducted among patients admitted to French emergency department for alcohol consumption-related disorders. Alcoholism, clinical and experimental research. 2010; 34(7): 1235-1245.

[26] Macauley K, Plummer L, Bemis C, Brock G, Larson C, Spangler J. Prevalence and Predictors of Anxiety in Healthcare Professions Students. Health Professions Education. 2018; 4(3): 176-185.

[27] Kavakci, Onder, Semiz, Murat, Kartal, Aysegul, Dikici, Ayfer, Kugu, Nesim. Test anxiety prevalance and related variables in the students who are going to take the university entrance examination. Dusunen Adam: The Journal of Psychiatry and Neurological Sciences. 2014; 27: 301-307.

[28] Rajiah, Kingston. Relationship of Test Anxiety, Psychological Distress and Academic Motivation among First Year Undergraduate Pharmacy Students. International Journal of Applied Psychology. 2014; 4 (2): 68-72.

[29] Fakhari, Ali, Kheradmand, Niloufar, Dolatkhah, Neda. Sleep Duration the Night before an Exam and Its Relationship to Students' Exam Scores. British Journal of Medicine and Medical Research. 2016; 15(8): 1-6.

[30] Akbari V, Asayesh H, Sharififard F, Qorbani M, Elahi A, Heidarpour A. Breakfast consumption as a test anxiety predictor among paramedical students. Journal of nursing and Midwifery sciences. 2020; 7: 47-51.

[31] Pines, Ayala, Gal, Reuven. The Effect of Food on Test Anxiety. Journal of Applied Social Psychology. 2006; 7: 348 - 358.

[32] Ahadi Z, Kelishadi R, Qorbani M. et al. Association of Breakfast Intake with Psychiatric Distress and Violent Behaviors in Iranian Children and Adolescents: The CASPIAN- IV Study. Indian J Pediatr. 2016; 83: $922-929$. 